\author{
S. Sobieszczyk ${ }^{1}$, R. Klotzke ${ }^{2}$ \\ ${ }^{1}$ Gdansk University of Technology, Faculty of Mechanical Engineering, Department \\ of Mechanical Engineering and Mechatronics, 80-233 Gdansk, Poland \\ ${ }^{2}$ Ship Design and Research Centre, Wały Piastowskie 1, 80-958 Gdańsk, Poland \\ rafal.klotzke@cto.gda.pl
}

\title{
NANOTUBULAR TITANIUM OXIDE LAYERS FOR ENHANCEMENT OF BONE-IMPLANT BONDING AND BIOACTIVITY
}

\begin{abstract}
Titanium and titanium alloys are frequently used in orthopaedic implants in load bearing situations because they possess favourable properties, such as a good ductility, tensile and fatigue strength, modulus of elasticity matching that of bones, low weight, and good biocompatibility. The drawback of Ti implants is their poor osseointegration and osteoconductive properties. The present paper describes the techniques to improve the bioactivity of titanium and enhance the bone-implant bonding ability by the electrochemical anodization to fabricate titania nanotube arrays $\left(\mathrm{TiO}_{2}\right)$. The naturally formed oxide layer has bio-inert character and does not readily form a strong interface with surrounding tissue. It has been proved that osseointegration of titanium implants can be improved by rough surfaces of Ti implants [1,2]. The nanotubular surface enhances adhesion, growth and differentiation of the cells. The nanotubular arrays increase the roughness of titanium implants on the nanoscale, providing the surface similar to that of a human bone. Bone-forming cells tend to adhere to the surfaces that are similar to natural bone both in chemistry and roughness. Nanotubular layers provide a high surface-to-volume ratio with controllable dimensions which are able to differentiation of mesenchymal stem cells into osteoblastic cells. Moreover, the anodized nanotubular arrays on titanium surface can be used as reservoirs for drugs (antiinflammatory, and improving bone-growth) with prolonged drug release ability. Also, there is possibility to further enhance bioactivity of titanium implant with nanotubular surface by hydroxyapatite deposition into the titania nanotubes which further promotes bone ingrowth. The application of nanotubular structures of oxide layers can be optimized taking into consideration some important parameters as osseointegration rate and interface strength determined by nanotube mean size and length.

The paper critically reviews so far investigations focused on nanooxidation of titanium and titanium alloys. The numerical model of nanotubular arrays with the use of Finite Element Method (FEM) is proposed for an assessment of the load transfer and stress distribution under applied loading which could be a critical factor when considering the described application of nanotubes.
\end{abstract}

Keywords: nanotubes arrays, bioactivity, anodic oxidation, bone

\section{INTRODUCTION}

Present orthopaedic bone implants have a limited life-time, up to 10-15 years, due to a variety of reasons as extensive inflammation or poor osseointegration. Titanium and its alloys are very promising biomaterials for bone tissue implants as they possess good 
physicochemical stability, mechanical integrity, good biocompatibility and excellent corrosion resistance in application as a bone implant material [3]. They also have an excellent strength-to-weight ratio. The drawback of titanium materials is their bioinert character, which results in no chemical connection to the bone or lack of actively induction of bone growth. Therefore, various surface modifications methods of bioactivation of titanium implants have been carried out to enhance the bone-titanium implant bonding.

Nowadays, the accurately defined surface structure of biomaterials is recognized as a main strategy in the design of the new generation of bone implants. Those implants should have a bioactive surface layer that has high surface area for enhanced bonding yet should be thin enough to minimize delamination which leads to implant loosening, and in consequence, to the implant failure.

Present findings indicate that titanium and its alloys with the vertically aligned selforganized titanium oxide nanotube arrays are the most appropriate biomaterials due to the large surface area and the defined geometry [4,5]. The nanotubular titania arrays can act as an intermediate layer for calcium phosphate deposition, thus improving the bond strength between apatite and titanium substrate and enhance bioactivity and boneimplant bonding.

\section{NANOTUBULAR TITANIUM OXIDE LAYER}

Natural and non-uniform oxide layer on titanium and its alloys does not protect the implant sufficiently in biological environments, so the surface of titanium needs to be modified. One of the most popular method of surface modification is electrochemical anodization [6]. The electrochemical anodization in fluoride containing solutions results in nanotubular titanium oxide layer on the titanium surface. Titanium and titanium alloys with anodic tubular oxide layer are very promising materials considering them as high performance biomedical materials, because they have excellent physical and chemical properties as well as biocompatibility $[2,7]$.

\section{Nanotubes formation}

The exact mechanism of nanotube formation (Fig.1) by electrochemical anodization is still unclear and remains a subject of very intensive research $[5,8,9]$. The $\mathrm{TiO}_{2}$ nanotube arrays formation in $\mathrm{F}^{-}$- containing electrolytes is a result of two competing electric field-assisted processes: hydrolysis of $\mathrm{Ti}$ metal to form $\mathrm{TiO}_{2}$ and chemical dissolution of $\mathrm{TiO}_{2}$ at the oxide/electrolyte interface (Fig.2). There are three stages which generally explain the $\mathrm{TiO}_{2}$ tubular growth, as explained in details by Crawford et al.[9]:

- Initial formation of the oxide barrier layer, where compact oxide film is created, accompanied by the decrease in anodic current density until it reaches the steady state.

- Formation of uniformly distributed pores by chemical dissolution of barrier oxide layer and increase in current density.

- Separation of interconnected pores into ordered nanotubes as a result of simultaneous growth of voids (regions between pores which are susceptible to field-assisted oxidation/dissolution) and pores [10]. 
(a)

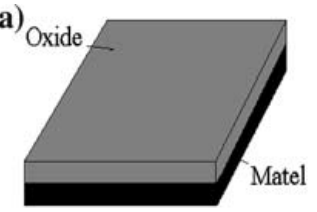

(d)

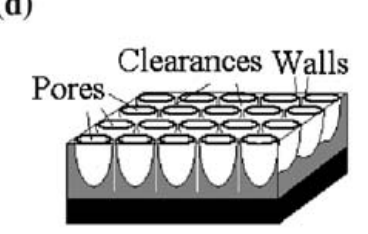

(b)

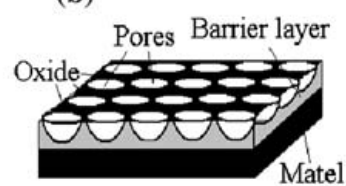

(c)

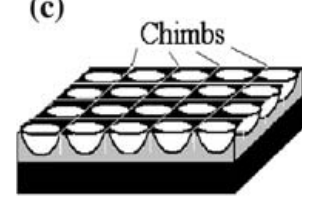

(e) Clearances Walls

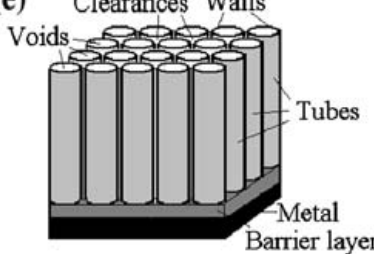

Fig. 1. Schematic diagram of the evolution of titania nanotubes in anodization: (a) oxide layer formation; (b) pore formation on the oxide layer; (c) chimbs' formation between pores; (d) growth of the pores and the chimbs; (e) fully developed titania nanotubes arrays [11]

\section{Effect of electrolyte parameters}

The electrochemical anodization may be carried out in different electrolytes which are aqueous, organic, polar organic or ethylene-glycol, resulting in different nanotubes geometries [12]. In many electrolytes, tubes can be grown with diameters of about 50$100 \mathrm{~nm}$ and at anodic voltage range between $10 \mathrm{~V}$ and $20 \mathrm{~V}[5,13]$.

In glycerol solutions [14], both the water content and fluoride content determine the tube growth kinetics. Additionally, nanotubes layer grown at $40 \mathrm{~V}$ have a crystalline anatase structure already in the as-formed state, whereas for different types of electrolytes used, to convert the amorphous tubes into crystalline anatase or rutile phase, usually annealing is necessary [15].
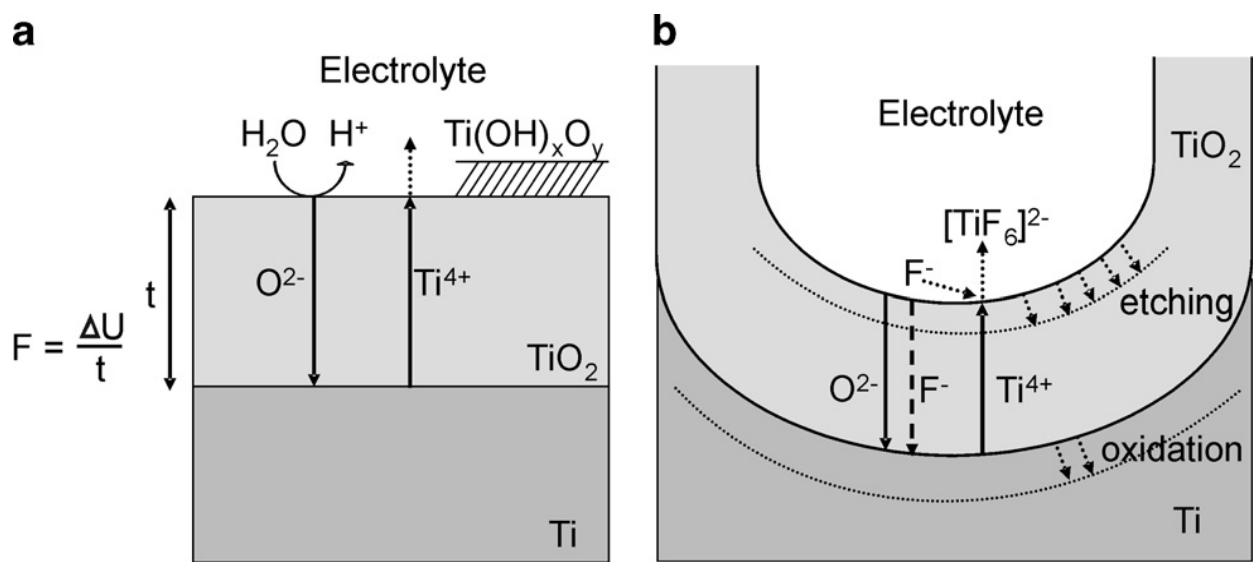

Fig. 2. Schematic representation of processes in $\mathrm{TiO}_{2}$ nanotube formation during anodization: a) in absence of fluorides; b) in presence of fluorides [10]

Apart of the type electrolyte used, the electrochemical parameters play an important role in determining the tube morphology and structure. The structure of nanotubular $\mathrm{TiO}_{2}$ arrays depend on the voltage applied during anodic oxidation due to the equilibrium between electrochemical formation of titania and chemical dissolution of titania in fluoride-containing electrolytes [16]. The investigations indicated that an increase of 
applied voltage from 10 to $25 \mathrm{~V}$ resulted in an increasing average tube diameter from 30 $\mathrm{nm}$ to $150 \mathrm{~nm}$ (e.g. in case of anodization in $1 \mathrm{M} \mathrm{H}_{2} \mathrm{SO}_{4}$ and $0.15 \mathrm{wt} . \% \mathrm{HF}$ ) [17]. The tube diameter and thickness can be controlled by changing the anodization time, as reported by Tsuchiya at al.[18], where in neutral fluoride containing $\left(\mathrm{NH}_{4}\right)_{2} \mathrm{SO}_{4}$ electrolyte an increase of the anodization time from $3 \mathrm{~h}$ to $10 \mathrm{~h}$ resulted in a tube length increase of $58 \%$ (the tube length of $1.7 \mu \mathrm{m}$ to $2.7 \mu \mathrm{m}$, respectively). In addition, there is a thinning effect for nanotubes at more acidic $\mathrm{pH}$ values which can be attributed to accelerated chemical dissolution of the tube walls [7]. Furthermore, the current density plays a significant role in nanotube formation with respect to tube diameter and morphology. Kaneco et al.[19] noticed that current density increased from 10 to 30 $\mathrm{mA}^{*} \mathrm{~cm}^{-2}$ resulting in enlargement of the tube diameter from 30 to $145 \mathrm{~nm}$ in fluorinated methanol and water mixture electrolytes.

\section{Biocompatibility and bioactivity of titanium nanotubes oxide layer}

The essential requirement for an implant to bond to the living bone is the formation of bone-like apatite on its surface when implanted in the body. The apatite layer will promote the tissue growth adjusted to the implant and the formation of strong bond between the tissue and the material after the implantation.

Different surface modifications methods have been developed to improve bioactivity, osteoconductivity and osseointegration of titanium implants. The nanotubular layer has an ability to enhance osteoblasts' functions providing necessary fluids in spaces between the nanotubes in similar way to human bone growth where body fluids provide substances sustaining cells to preserve life functions. Also, the nanotubular layer provides a very high surface-to-volume ratio for more cells adhesion.

To evaluate bioactivity of a biomaterial at in vivo conditions, a simulated body fluid (SBF), with almost the same ion concentrations as those of human blood plasma, can be used [20]. It has been proposed that the material, which forms bone-like apatite on their surface in SBF, can also form apatite in a living body and can bond to the bone through the apatite layer [21].

\section{HA DEPOSITION INTO TITANIUM OXIDE NANOTUBES}

Hydroxyapatite $\left(\mathrm{HA} ; \mathrm{Ca}_{10}\left(\mathrm{PO}_{4}\right)_{6}(\mathrm{OH})_{2}\right)$ is a ceramic material with a chemical similarity to the mineral component of human bones and teeth. Also, HA exhibits bioactive behaviour and integrates into living tissue by the same processes as active in remodelling of healthy bone. This process leads to the physicochemical bond between the implant and the bone. Dense HA coatings on titanium implants have some drawbacks like the possibility of delamination from the substrate [22].

The nanotube arrays contribute to the increase in surface roughness and surface area provided for the subsequent hydroxyapatite coating deposition. Also, the nanotube structure serves as an excellent anchorage for HA coating which improves the mechanical interlocking of the implant to the bone. There are some reports on the preparation of HA coating on the $\mathrm{TiO}_{2}$ nanotubes using methods, like cathodic deposition [22], electrodeposition [23], or biomimetic deposition [24]. Calcium 
phosphate deposition onto nanotubular $\mathrm{TiO}_{2}$ layer by electrodeposition process is conducted in electrolytes containing salts (Table 1). In order to achieve more uniform HA coating with higher bond strength above $16 \mathrm{MPa}$ ), the alkali treatment in $0.5 \mathrm{M}$ $\mathrm{NaOH}$ before deposition of HA can be used [23]. As a result of alkali treatment, the titanates appear at the neck of titania nanotubes enhancing the formation of HA during electrodeposition process. It was shown, that bioactive hydroxyapatite coatings on as anodized titania nanotubes could be obtained by a biomimetic method without another surface treatment [25]. The apatite deposition can be evaluated by immersion test in simulated body fluid (SBF), where calcium and phosphate ions are rapidly deposited onto the surface of the nanotubular layer. It is noteworthy, that when biomimetic technique is applied the crystal shape of HA coating is spherical and in electrochemical method becomes hexagonal.

Table 1. Electrolytes for calcium phosphate deposition

\begin{tabular}{|l|c|c|c|}
\hline \multicolumn{1}{|c|}{ Electrolyte } & $\begin{array}{c}\text { Temp. } \\
{\left[{ }^{0} \mathrm{C}\right]}\end{array}$ & $\mathrm{pH}$ of electrolyte & Reference \\
\hline $0.04 \mathrm{~m} \mathrm{Ca}\left(\mathrm{NO}_{3}\right)_{2}+0.027 \mathrm{~m}$ & 25 & 4.5 & {$[26]$} \\
$\mathrm{NH}_{4} \mathrm{H}_{2} \mathrm{PO}_{4}+0,1 \mathrm{~m} \mathrm{NaNO}_{3}$ & & & \\
\hline $\mathrm{Ca}(\mathrm{OH})_{2}+0.02 \mathrm{~m}\left(\mathrm{NH}_{4}\right)_{2} \mathrm{HP}_{4}$ & 25 & 4.5 & {$[7]$} \\
\hline $0.04 \mathrm{~m} \mathrm{Ca}\left(\mathrm{NO}_{3}\right)_{2}+0.027 \mathrm{~m}$ & 65 & 4 & {$[22]$} \\
$\mathrm{NH}_{4} \mathrm{H}_{2} \mathrm{PO}_{4}+0.5 \mathrm{M} \mathrm{NaCl}$ & & 6 & \\
\hline
\end{tabular}

Very recently, Kodama et al. [7] proposed quite simple alternative immersion method (AIM) treatment which preloads titania nanotubes with synthetic HA by a procedure of repeated cycles of immersion in saturated $0.02 \mathrm{~mol} / \mathrm{dm}^{3} \mathrm{Ca}(\mathrm{OH})_{2}$ and $0.02 \mathrm{~mol} / \mathrm{dm}^{3}$ $\left(\mathrm{NH}_{4}\right)_{2} \mathrm{HPO}_{4}$ at room temperature, achieving flake-like deposits on the nanotube layer as well as inside each single tube.

\section{FILLING OF NANOTUBES}

Nanotubes of titanium oxide can serve as a reservoir and drug delivery system for antiinfection, anti-inflammation and pro-bone growth drugs at the site of implantation [27]. It has been found that by additional surface modification with plasma polymerization, the control over reduction of pore diameter and immobilization of some molecules can be achieved [28]. The method involves deposition of a plasma layer rich in reactive amine groups from allylamine which are favourable for cell adhesion. Additionally, the titania nanotubes arrays can be loaded with different amount of drugs significantly reducing bacterial adhesion on the implant surface. It was proven, that when filling the tubes with gentomicin, commonly used aminoglycoside antibiotic to prevent bacterial infection around the implant, the osteoblast proliferation was enhanced [29]. The nanotubes can be filled with antibiotics via simplified lyophilisation method where solution is pipped onto the nanotubes surface and dried under vacuum at room temperature or soaking the implant in the combination of drug and SBF solutions [30]. 


\section{FEM MODELLING OF MECHANICAL PROPERTIES OF NANOTUBULAR ARRAYS}

It is important to characterize the mechanical behaviour of nanotube arrays to elucidate deformation mechanism, because a long-term structural stability for materials implanted in the human body is crucial. To assess the bone - implant integration and the bond strength between the coating and substrate, several mechanical tests were applied, like adhesion test by pull-off method using scratch tester [31], tensile test [32], compressive strength test on universal testing machine [33], or nanoindentation which is the most appropriate method for a very thin coating with the thickness less than $10 \mu \mathrm{m}$ [34]. The authors observed that coating delamination occurred on unloading due to residual stresses for a very thin coating (nanotubes length up to $250 \mathrm{~nm}$ ) and not for thicker coatings $(600-650 \mathrm{~nm})$.

Strength analysis of titania oxide nanotubular structure were performed with FEM program Patran 2008r2 as the pre- and postprocessor and with MD Nastran R3c as the solver. The FEM model was entirely generated with SOLID elements (Hex8 and Wedge6). The model reached 1609512 degrees of freedom.

The topology of the FEM model is shown on Figure 3. The boundary conditions were set in such a way, that all degrees of freedom were locked on the bottom edge of the base. The length of the base Ti was so selected, that the assumed boundary conditions are not influencing the results at connection between nanotubes and the base.

The material properties used in the analysis are shown in Table 2 and the material distribution in the model is shown on Fig. 4.

Following five load conditions were analyzed:

- LC1 - deadweight of the structure (only gravitational acceleration),

- LC2 - deadweight of the structure and load of $22 \mu \mathrm{N}$,

- LC3 - deadweight of the structure and load of $50 \mu \mathrm{N}$,

- LC4 - deadweight of the structure and load of $100 \mu \mathrm{N}$,

- LC5 - deadweight of the structure and load of $150 \mu \mathrm{N}$.

The load was delivered as the pressure distributed on the upper edge of each nanotube, which is shown in Figure 5.

The loads are the global loads distributed on the entire structure - in presented case on 22 nanotubes. Table 3 shows values of displacements [nm] and Von Misses stresses $[\mathrm{Pa}]$ in nanotube elements for each load condition.

Maximum stresses occurred on interfaces between nanotubes and the base, that is shown in Figure 6 as the example for load condition LC2.

The proposed model will be developed for different geometries of nanotubular arrays.

As seen, the deformation under the applied load could be quite high. Therefore the application of more rigid nanostructures may be necessary followed by FEM calculations of mechanical behaviour.

Table 2. Material properties used in analysis [34]

\begin{tabular}{|c|c|c|c|}
\hline & $\mathrm{TiO}_{2}$ & $\mathrm{Ti}$ & Nanotube \\
\hline Elastic Modulus [GPa] & 140 & 110 & 40 \\
\hline Poissin Rario [-] & 0,34 & 0,34 & 0,31 \\
\hline Density [g/m ${ }^{3}$ ] & 3,9 & 4,5 & 3,89 \\
\hline
\end{tabular}




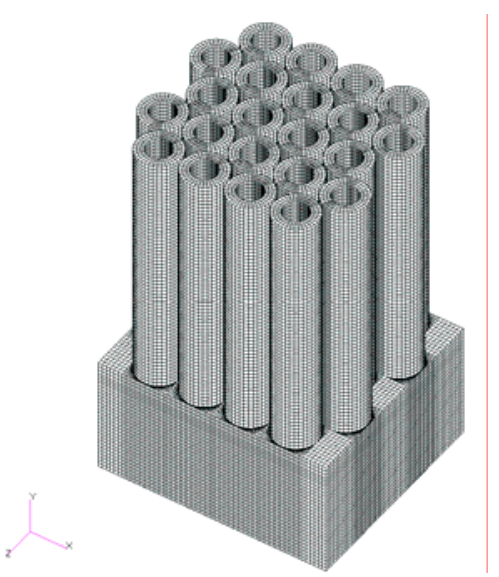

Fig. 3. Numerical FEM model for titania oxide nanotubular structure

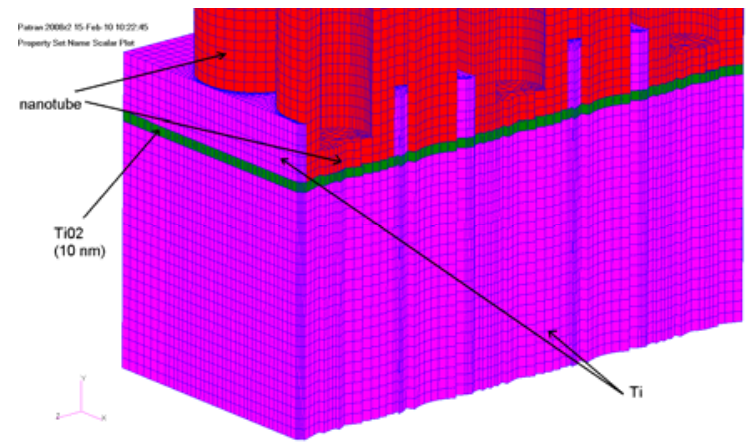

Fig. 4. Material distribution in the model

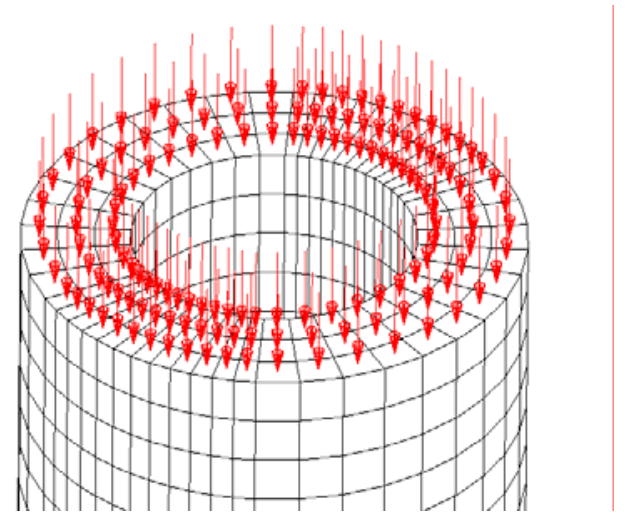

Fig. 5. Loading of single nanotube

Table 3. Summary of analysis results

\begin{tabular}{|c|c|c|}
\hline Load cases & Deformation [nm] & V. Misses stress [Pa] \\
\hline LC1 & 0,268 & $4,06^{*} 10^{7}$ \\
\hline LC2 & 2,86 & $2,71^{*} 10^{8}$ \\
\hline LC3 & 6,16 & $5,65^{*} 10^{8}$ \\
\hline LC4 & 12,0 & $1,09^{*} 10^{9}$ \\
\hline LC5 & 17,9 & $1,61^{*} 10^{9}$ \\
\hline
\end{tabular}




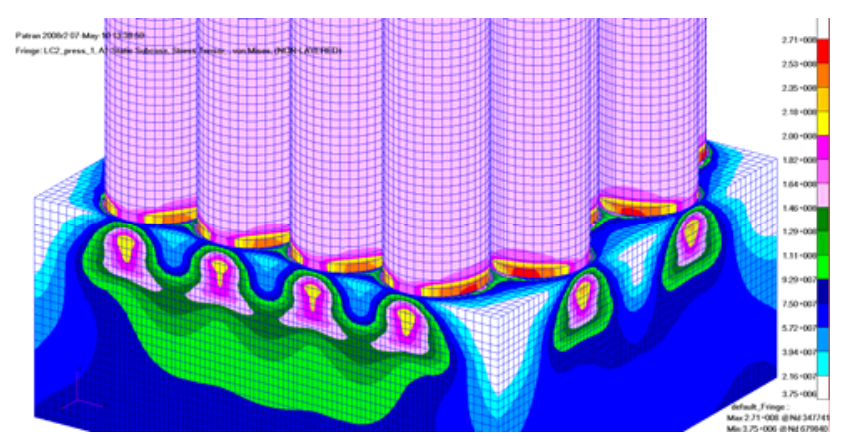

Fig. 6. Von Misses stresses [Pa] at the interface nanotubular layer/substrate under the loading of $1 \mu \mathrm{m}$

\section{CONCLUSIONS}

Nanotubular titanium oxide layer enables implant-bone bonding better than conventional micro-roughened titanium surface enhancing mineral formation, adhesion of osteoblasts and bone growth in vivo. It has been proven that cells respond positively to nanotopography which is similar to the natural roughness of human bone. Boneforming cells tend to adhere more readily to the surface if it is chemically and physically similar to natural bone, thus nanotubular titanium oxide layer is a promising biologically-inspired method to promote osteoblast functions and enhance implant-bone bonding. The use of titanium oxide nanotube arrays formed by simple anodic oxidation is desirable for enhancing the implant-bone bonding by reducing time for osseointegration, enhancing cell proliferation and cell-material interaction, providing sustained and controlled drug reservoir and release, preventing infections and inflammatory reactions after the implantation and increasing implant life-time.

The proposed FEM model allows to investigate the effect of applied load on the stress and strain behaviour of nanotubular array. Based on the numerical simulation results, the optimal geometry of nanotubes can be derived considering the loading conditions at the implantation site of the porous implant with nanotubular coating layer.

The paper summarizes the so far investigations focused on nanooxidation of titanium and titanium alloys used as orthopaedic materials. In order to maintain the desired properties of nanooxide arrays it is necessary to analyse whether the nanotubes will be able to carry the possible loads resulting from surgery procedures and post-implantation conditions.

\section{REFERENCES}

1. Hazan R., Sreekantan S., Khalil A.A., Nordin I., Mat I.: Surface Engineering of Titania for Excellent Fibroblast 3T3 Cell-Metal Interaction, Journal of Physical Science. 20(1) (2009) $35-47$.

2. Oh H-J., Lee J-H., Kim Y-J, Suh S-J., Chi Ch-S.: Surface characteristics of porous anodic $\mathrm{TiO}_{2}$ layer for biomedical applications, Materials Chemistry and Physics, 109 (2008) 1014. 
3. Geetha M., Singh A.K., Asokamani R., Gogia A.K.: Ti Based Biomaterials, the Ultimate Choice For Orthopaedic Implants - A Review, Progress in Materials Science 54 (2009) 397-425.

4. Kim S.E., Lim J.H., Lee S.Ch., Nam S-Ch., Kang H-G., Choi J.: Anodically nanostructured titanium oxides for implant applications. Electrochimica Acta 53, (2008) 4846-4851.

5. Sobieszczyk S.: Self-organized Nanotubular Oxide Layer on Ti and Ti alloys. Advances in Materials Science, 9(2), 25-41 (2009).

6. Mor G.K., Oomman K., Varghese K., Paulose M., Shankar K., Grimes C.A.:A review of highly ordered, vertically oriented $\mathrm{TiO}_{2}$ nanotube arrays: Fabrication, material properties, and solar energy applications, Solar Energy Materials \& Sollar Cells 90, (2006) 2011-2075.

7. Kodama A., Bauer S., Komatsu A., Asoh H., Ono S., Schmuki P.: Bioactivation of titanium surfaces using coatings of $\mathrm{TiO}_{2}$ nanotubes rapidly pre-loaded with synthetic hydroxyapatite. Acta Biomaterialia 5(6), (2009) 2322-2330.

8. Petukhov D.I., Eliseev A.E., Kolesnik I.V., Napolskii K.S., Lukashin A.V., Tretyakov Y.D., Grigoriev S.V., Grigorieva N.A., Eckerlebe H.: Formation mechanism and packing options in tubular anodic titania films Microporous and Mesoporous Materials 114, (2008) 440-447.

9. Crawford G.A., Chawla N.: Porous hierarchical $\mathrm{TiO}_{2}$ nanostructures: Processing and microstructure relationships. Acta Materialia 57, (2009) 854-867.

10. Macak J.M., Tsuchiya H., Ghicov A., Yasuda K., Hahn R., Bauer S., Schmuki P.: Current Opinion in Solid State and Materials Science 11, (2007) 3-18.

11. Tian T., Xiao X., Liu R., She H., Hu X.: Study on titania nanotube arrays prepared by titanium anodization in $\mathrm{HN}_{4} \mathrm{~F} / \mathrm{H}_{2} \mathrm{SO}_{4}$ solution. J Materials Sc, 42, (2007) 5539-5542.

12. Regonini D., Bowen C.R., Stevens R.: Nucleation and early growth of anodized $\mathrm{TiO}_{2}$ film. J Mater. Res. 23(8), (2008) 2116-2124.

13. Yu X., Li Y., Wlodarski W., Kandasamy S., Kalantar-Zadeh K.: Fabrication of nanostructured $\mathrm{TiO}_{2}$ by anodization: A comparison between electrolytes and substrates. Sensors and Actuators, B 130, (2008) 25-31.

14. Macak J.M., Hildebrand H., Marten-Jahns U., Schmuki P.: Mechanistic aspects and growth of large diameter self-organized $\mathrm{TiO}_{2}$ nanotubes. J Electroanalytical Chemistry 621, (2008) 254-266.

15. Zhao J., Wang X., Sun T., Li L.: Crystal phase transition and properties of titanium oxide nanotube arrays prepared by anodization. J Alloys and Compounds, 434-435, (2007) 792795.

16. Kuromoto N.K., Simao R.A., Soares G.A.: Titanium oxide films produced on commercially pure titanium by anodic oxidation with different voltages. Materials Characterization 58, (2007) 114-121.

17. Bestetti M., Franz S., Cuzzolin M., Arosio P., Cavallotti P.L.: Structure of nanotubular titanium oxide templates prepared by electrochemical anodization in $\mathrm{H}_{2} \mathrm{SO}_{4} / \mathrm{HF}$ solutions. Thin Solid Films, 515, (2007) 5253-5258.

18. Tsuchiya H., Berger S., Macak J.M., Munoz A.G., Schmuki P.: A new route for the formation of self-ordered anodic porous alumina in neutral electrolytes. Electrochemistry Communications 9, (2007) 545-550.

19. Kaneco S., Chen Y., Westerhoff P., Crittenden J.C.: Fabrication of uniform size titanium oxide nanotubes: Impact of current density and solution conditions. Scripta Materialia 56, (2007) 373-376. 
20. Park J-H., Lee Y-K., Kim K-M., Kim K-N.: Bioactive calcium phosphate coating prepared on $\mathrm{H}_{2} \mathrm{O}_{2}$-treated titanium substrate by electrodeposition. Surface \& Coatings Technology 195, (2005) 252-257.

21. Lee J-Y, Choo J-E., et al.: Assembly of collagen-binding peptide with collagen as a bioactive scaffold for osteogenesis in vitro and in vivo. Biomaterials 28, (2007) 4257-4267.

22. Raja K.S., Misra M., Paramguru K.: Deposition of calcium phosphate coating on nanotubular anodized titanium. Materials Letters, 59, (2005) 2137-2141.

23. Kar A., Raja K.S., Misra M.: Electrodeposition of hydroxyapatite onto nanotubular $\mathrm{TiO}_{2}$ for implant applications. Surface \& Coatings Technology, 201, (2006) 3723-3731.

24. Xiao X., Tian T., Liu R., She H.: Influence of titania nanotube arrays on biomimetic deposition apatite on titanium by alkali treatment. Mat Chem \& Physics 106 (2007) 27-32.

25. Feng B., Chu X.., Chen J., Wang J., Lu X., Weng J.: Hydroxyapatite coating on titanium surface with titania nanotube layer and its bond strength to substrate. J Porous Materials (2009) 1380-2224.

26. Wang Y., Tao J., Wang L., He P., Wang T.: HA coating on titanium with nanotubular anodized $\mathrm{TiO}_{2}$ intermediate layer via electrochemical deposition. Trans Met. Soc. China 18 (2008) 631-635.

27. Aninwene II G.E.., Yao Ch., Webster T.J.: Enhanced osteoblast adhesion to drug-coated anodized nanotubular titanium surfaces. Int. J. Nanomedicine. 3(2), (2008) 257-264.

28. Vasilev K., Poh Z., Kant K., Chan J., Michelmore A., Losic D.: Tailoring the surface functionalities of titania nanotube arrays. Biomaterials, 31, (2010) 532-540.

29. Popat K.C., Eltgroth M., LaTempa T.J., Grimes C.A., Desai T.A.: Decreased Staphylococcus epidermis adhesion and increased osteoblast functionality on antibioticloaded titania nanotubes. Biomaterials. 28, (2007) 4880-4888.

30. Gultepe E., Nagesha D., Sridhar S., Amiji M.: Nanoporous inorganic membranes or coatings for sustained drug delivery in implantable devices, Advanced Drug Delivery Reviews, Article in progress, doi: 10.1016/j.addr.2009.11.003 (2009).

31. Zhang W., Li G., Li Y., Yu Z., Xi Z.: Fabrication of $\mathrm{TiO}_{2}$ nanotube arrays on biologic titanium alloy and properties,.Trans. Nonferrous Met. Soc. China, 17, (2007) 692-695.

32. Narayanan R., Kwon R-Y., Kim K-H.: $\mathrm{TiO}_{2}$ nanotubes from stirred glycerol/ $\mathrm{NH}_{4} \mathrm{~F}$ electrolyte: Roughness, wetting behaviour and adhesion for implant applications, Materials Chemistry and Physics 117., (2009) 460-464.

33. Lee J-H., Kim H-E., Koh Y-H.: Highly porous titanium (Ti) scaffolds with bioactive microporous hydroxyapatite/ $\mathrm{TiO}_{2}$ hybrid coating layer. Materials Letters 63 (2009) 19951998.

34. Crawford G.A., Chawla N., Das K., Bose S., Bandyopadhyay A.: Microstructure and deformation behaviour of biocompatible $\mathrm{TiO}_{2}$ nanotubes on titanium substrate, Acta Biomaterialia, 3 (2007) 359-367. 